\title{
SIGNIFICANDO OS SENTIDOS DA VIDA NA FORMAÇÃO DOS PROFISSIONAIS DE SAÚDE: COM A PALAVRA OS ESTUDANTES
}

\author{
Rita de Cássia Duarte Lima ${ }^{1}$, Heletícia Scabelo Galavote², Talita Dourado Schwartz ${ }^{3}$, Maria Cristina Ramos ${ }^{4}$, Thiago \\ Nascimento do Prado ${ }^{5}$, Ethel Leonor Noia Maciel ${ }^{1}$
}

RESUMO: Este artigo analisa a experiência desenvolvida em uma nova disciplina do currículo da Graduação em Enfermagem implantada em 2006: Enfermagem e Sociedade. Realizaram-se vivências em três oficinas por semestre e encontros semanais com os alunos do primeiro período da Graduação em Enfermagem, durante os dois semestres de 2006 e um de 2007, com três questões: Qual o sentido da vida? Qual o sentido de tornar-se profissional de saúde? Por que escolheu Enfermagem? A vida foi significada como teia de relações, emoções e experiências. A escolha da profissão Enfermagem pelos acadêmicos é resultado da percepção do papel do enfermeiro, das facilidades de acesso ao emprego e da possibilidade de ajudar as pessoas. Dar novos significados ao processo de formação em saúde envolve novos conteúdos que contemplem as relações entre Enfermagem, sociedade e cuidado.

PALAVRAS-CHAVE: Educação; Currículo; Educação em enfermagem.

\section{MAKING SENSE OF FEELINGS ABOUT LIFE IN THE FORMATION OF HEALTH PROFESSIONALS: IN THE WORDS OF STUDENTS}

\begin{abstract}
This article analyses the experiences which developed in a new discipline in the curriculum of the undergraduate Nursing course implanted in 2006: Nursing and Society. During the two semesters of 2006 and one of 2007 , students from the first year of the undergraduate nursing course got together in weekly meetings plus three workshops per semester to discuss three questions: What is the meaning of life? What does it mean to become a health professional? Why did you choose Nursing? Life was seen as a web of relationships, emotions and experiences. The choice of the nursing profession by the students is a result of the perception of the role of the nurse, the facilities to enter work and the possibility of helping people. Finding new meanings in the process of training health professionals involves new content which looks at the relationships between Nursing, society and care.
\end{abstract}

KEYWORDS: Education; Curriculum; Education and Nursing.

\section{SIGNIFICANDO LOS SENTIDOS DE LA VIDA EN LA FORMACIÓN DE LOS PROFESIONALES DE SALUD: CON LA PALABRA LOS ESTUDIANTES}

\begin{abstract}
RESUMEN: Este artículo analiza la experiencia desarrollada en una nueva disciplina del currículo de la Graduación en Enfermería implantada en 2006: Enfermería y Sociedad. Fueron realizadas vivencias en tres encuentros por semestre y clases semanales con los alumnos del primer periodo de la Graduación en Enfermería, durante los dos semestres de 2006 y un de 2007, con tres cuestiones: ¿Cuál el sentido de la vida? ¿Qué significa tornarse profesional de salud? ¿Por que elegiste Enfermería? La vida fue significada como tela de relaciones, emociones y experiencias. El hecho de elegir Enfermería como profesión para los académicos es resultado de la percepción del papel del enfermero, de las facilidades de acceso al empleo y de la posibilidad de ayudar a las personas. Dar nuevos significados al proceso de formación en salud involucra nuevos contenidos que contemplen las relaciones entre Enfermería, sociedad y cuidado.
\end{abstract}

PALABRAS CLAVE: Educación; Currículo; Educación en enfermería.

\footnotetext{
${ }^{1}$ Enfermeira. Doutora em Saúde Coletiva. Professora do Departamento de Enfermagem e do Programa de Pós-Graduação em Saúde Coletiva da Universidade Federal do Espírito Santo-UFES.

${ }^{2}$ Enfermeira. Mestranda em Saúde Coletiva pela Universidade Federal Fluminense. Membro do NESC/UFES.

${ }^{3}$ Enfermeira. Mestranda em Saúde Coletiva na UFES. Membro do NESC/UFES.

${ }^{4}$ Enfermeira. Doutoranda em Educação. Professora do Departamento de Enfermagem da UFES.

${ }^{5}$ Enfermeiro. Mestrando em Doenças Infecciosas na UFES. Membro do NESC/UFES.
}

Autor correspondente:

Rita de Cássia Duarte Lima

Universidade Federal do Espírito Santo

R. Artur Czartorysk, 315 - 29060-370 - Vitória-ES-Brasil

E-mail: ritacdl@uol.com.br

Recebido: 08/12/09

Aprovado: 24/11/10 


\section{INTRODUÇÃO}

Este artigo analisa a experiência vivenciada na disciplina Enfermagem e Sociedade, iniciada em 2006, pertencente ao currículo do Curso de Graduação em Enfermagem da Universidade Federal do Espírito Santo (UFES). Essa disciplina é produto de várias reflexões e debates fomentados em diversos cenários, como os seminários nacionais realizados na década de 90 para discutir o currículo de Enfermagem e, no nível local, as discussões e experiências vividas na trajetória do curso. A Graduação em Enfermagem da UFES foi implantada em 1976 e, até a metade da década de 90, era o único curso de Graduação em Enfermagem no Estado do Espírito Santo. Desde sua criação, recebe 30 estudantes por semestre e possui, atualmente, cerca de 250 estudantes regularmente matriculados.

No momento, desenvolvendo o quarto currículo, o curso tem buscado construir a integração curricular, compreendendo-a como um processo dialético que comporta percepções, contextos e olhares diferenciados sobre a ação ensino-aprendizagem na formação dos profissionais de Enfermagem/Saúde. Com as mudanças curriculares, procura-se romper com um modelo de ensino ainda impregnado da lógica cartesiana, determinado pela linearidade dos conteúdos, dos pré-requisitos e da hierarquia das disciplinas, e muito focado no aspecto biológico e na doença, a partir da transmissão de conteúdos e vivências cujos exemplos têm baixo poder de provocar reflexão e crítica por parte dos atores envolvidos.

Hoje estão consolidadas mudanças curriculares em todos os níveis de ensino no Brasil, pautadas nos princípios da integração, da interdisciplinaridade e da transversalidade na formação profissional. Contudo, a estrutura hierárquica e compartimentalizada dos departamentos e disciplinas colabora para reduzir o potencial de comunicação e a pactuação entre eles, o que gera baixa credibilidade perante os serviços de saúde e a sociedade ${ }^{(1)}$.

A incorporação das demandas sociais no processo de ensino-aprendizagem se apresenta como um desafio, pois requer a reconstrução de um modelo que tenha o estudante como cerne, valorizando seus saberes e práticas, e ressignificando a relação trabalhador-estudante-usuário ${ }^{(2)}$. Nesse contexto, destaca-se a importância de se consolidar redes institucionais que permitam a abertura de novos cenários de aprendizagem e que se constituam em espaços ricos de formação de sujeitos, implicados e apropriados dos seus processos reais de trabalho.

$\mathrm{O}$ atual currículo implementado no Curso de Enfermagem da UFES tem como enfoque norteador apreender a Enfermagem como uma ciência da saúde, percebida em uma perspectiva histórico-social, que busca conhecer o homem na sua integralidade, na sua relação com o meio, e respeitar a sua estrutura biopsicossocial e espiritual ${ }^{(3)}$. A disciplina Enfermagem e Sociedade é obrigatória, com carga horária de 60 horas, cuja competência a ser desenvolvida nos alunos é:

[...] apropriar-se dos fundamentos básicos da sociologia da saúde e antropologia cultural para compreender os diferentes fatores envolvidos no processo saúdedoença e analisar criticamente as relações entre saúde/ enfermagem $/$ sociedade $^{(3: 9)}$.

Ao se iniciar essa disciplina, no primeiro semestre de 2006, buscou-se apreender significados com alguns temas em mente para serem apresentados, tensionados, discutidos e pactuados com os estudantes.

O objetivo deste artigo é analisar a experiência desenvolvida na disciplina Enfermagem e Sociedade. Para tanto, foi fundamental captar com os estudantes, no desenvolvimento das atividades, os sentidos e significados da vida e da relação com os outros.

\section{METODOLOGIA}

Trata-se de um estudo qualitativo que privilegia o universo de significados, motivos, aspirações e as relações sociais na interação com crenças, valores, atitudes e subjetividades. Foram realizadas três oficinas por semestre letivo, durante os dois semestres de 2006 e um de 2007. Duas oficinas ocorreram nas duas primeiras semanas de aula, e a terceira, na última semana de aula. Para cada semestre participaram 30 estudantes, regularmente matriculados, totalizando 90 estudantes. O tema disparador foi "Os sentidos da vida". Nesse processo, os alunos puderam refletir e se expressar da forma que julgassem o mais pertinente para responder às seguintes questões: Qual o sentido/ significado da vida para cada um de vocês? Qual o sentido em tornar-se profissional de saúde? Dentre tantas escolhas na vida, por que Enfermagem?

As perguntas foram entregues por escrito, em um primeiro momento, e cada estudante apresentou suas respostas. No segundo momento, as perguntas foram entregues a grupos de três estudantes para serem res- 
significadas e apresentadas para o coletivo, a fim de que as respostas fossem compartilhadas e a discussão do tema emergisse para todo o grupo. Com autonomia para se expressar, os alunos utilizaram textos próprios e de outros autores, mensagens, poesias e músicas.

$\mathrm{Na}$ última semana de aula, as três questões retornaram para o debate na oficina prevista para o encerramento da disciplina. Vale ressaltar que, no transcorrer do semestre, essas questões (re) emergiram, ressignificando os sentidos da vida e da Enfermagem.

Os dados foram analisados à luz dos discursos produzidos pelos estudantes nas oficinas, tendo como pressuposto a possibilidade de se apreender os significados expressos pelos sujeitos. A análise do discurso permite conceber a linguagem não como evidência, mas como lugar da descoberta, de tensões, (des)velamentos, ou seja, lugar dos discursos, que não necessita ser único, homogêneo e harmônico ${ }^{(4)}$.

Este trabalho foi aprovado pelo Comitê de Ética do Centro de Ciências da Saúde da Universidade Federal do Espírito Santo, no dia 21 de dezembro de 2005, e todos os demais procedimentos éticos em pesquisa foram observados.

\section{Apresentando e discutindo significados e sentidos}

Ao responderem à pergunta "Qual o sentido/significado da vida para vocês", os estudantes construíram textos em que situam a vida como:

[...] um conceito multifacetado. É a essência do mundo, e cada ser humano tem um conceito diferente sobre a vida. (S1)

O próprio conceito de vida é polissêmico ${ }^{(5)}$ e, dessa forma, não existe significado, conceito ou definição tanto no mundo da ciência como no senso comum:

[...] a vida é a história de cada um de nós: o passado, o presente e o futuro. (S2)

A vida é sobre quem você ama, e quem você machuca. É sobre quem faz feliz ou infeliz, propositadamente. (S3)

A existência da vida envolve interações e interrelações $^{(6)}$. A vida pressupõe aprender, num desafio contínuo para cada nova circunstância que se apresenta no cotidiano. Ela é esse movimento trazido pelos estudantes de amar, machucar, ignorar, com controle e intencionalidade:

[...] a vida éfeita de perdas, coisas que passam e coisas que chegam. (S4)

Um dos estudantes nos apresentou o significado da vida pela dialética vida/morte:

[...] se vida é viver em busca do desconhecido, sabendo o inevitável caminho que há no fim, então vida não é vida: é morte. (S5)

A partir de Leonardo Boff ${ }^{(7)}$, apreendeu-se o significado da vida como um processo de auto-organização extremamente complexa da matéria e da energia do universo que forma a teia da vida. Dessa teia, os homens vão construindo suas identidades na sociedade em que vivem e morrem, o que vai implicar modos de vida que vão determinarão formas de nascer e morrer, de acolher e ser acolhido, de situar e se situar, de cuidar e ser cuidado em nossa sociedade. Nesse contexto, emergem também as escolhas que faremos na vida, e uma dessas será a profissional. Portanto, ganha sentido a interrogação: Por que a Enfermagem como profissão?

Pode-se perceber a expansão do papel profissional do enfermeiro como

[...] uma das profissões do futuro, com mercado de trabalho em franca expansão, conforme apontado na mídia. (S2)

Eu escolhi Enfermagem porque é um curso na área de saúde e eu sempre gostei de ajudar as pessoas quando elas precisam. (S8)

Assim, contraditoriamente, o cuidado ao doente se revelou como o grande mobilizador nas escolhas desses estudantes, ratificando a imagem social e cultural de que ser profissional de saúde é, antes de tudo, ser um cuidador de doenças/doentes e não um agente de promoção da saúde de pessoas com necessidades e sofrimentos distintos, que nem sempre estão relacionados com doenças.

O cenário dos serviços de saúde é o espaço de produção tanto de relações e disputas, quanto de bens e produtos. Qualquer que seja a abordagem ao usuário/ paciente, a relação que se estabelecerá será sempre a de uma pessoa atuando sobre a outra ${ }^{(8)}$. Posto isso, se somos moldados por processos de formação em par- 
tes, reproduzimos modelos que contribuem para que o indivíduo portador de necessidades de saúde tenha seus cuidados vinculados às partes e aos órgãos. Desta forma, diluem-se suas necessidades, muitas vezes representadas por agravos, doenças de partes fatiadas do corpo humano, produzindo-se o que tem se chamado de "descuidado"(9). Ao fragmentar o ato de cuidar em órgãos doentes, em partes do corpo adoecidas, perdese também o sentido de totalidade, de integralidade do homem; fortalece-se a sua desintegração.

O processo de cuidar do outro ganha sentido quando a existência das pessoas se torna "significativa para mim", independentemente do meu papel social e da pessoa a ser cuidada. São os sentimentos de importância e a solidariedade com o sofrimento do outro que nos levam a nos dedicar a ele, a participar do seu destino, de suas buscas, dos seus sofrimentos, dos seus afetos, dos seus sucessos, avanços e mesmo dos seus fracassos e limitações ${ }^{(10)}$.

\section{CONSIDERAÇÕES FINAIS}

As vivências e encontros tornaram-se um privilegiado espaço pedagógico de ressignificações e lugares de jogos de sentidos e espaços de expressão. Dar novos significados ao processo de formação, à vida e ao trabalho dos profissionais de saúde estimulou o estudante a trabalhar sentidos de alteridade, a se colocar no lugar do outro, na condição de estudante, de professor, de profissional e de usuário dos serviços de saúde.

Estar nesses lugares contribui para nos situar e situar o outro na dimensão do "como quero ser cuidado", de romper com a neutralidade diante do sofrimento alheio; em particular, em momentos em que as fragilidades da vida nos impõem permitir ao profissional de saúde "cuidar da minha vida", do meu destino, da minha saúde ou da minha doença. E serve, também, para ressignificar a morte como parte da vida, compreendendo que, para além do sofrimento que a ela subjaz, esses momentos podem significar aprendizados de atos de afeto e solidariedade com as vidas humanas.

Portanto, cabe (re)afirmar a importância, para a formação dos profissionais de saúde, de conteúdos que contemplem as relações entre Enfermagem, sociedade e cuidado em saúde. Isso permite pensar esses processos a partir da certeza de que as ações de cuidado em saúde, a ser ensinadas aos futuros profissionais, precisam incluir valores, desejos e compromissos com o cuidado e com o conhecimento, uma vez que $\mathrm{o}$ ato de cuidar do outro requer dimensões amplas e abrangentes.

\section{REFERÊNCIAS}

1. Mourão LC, Martins RCB, Vieira CM, Rossin E, L'Abbate S. Análise institucional e educação: reforma curricular nas universidades pública e privada. Educ Soc. 2007;28(98):181-210.

2. Oliveira GS, Koifman L, Pontes ALM. As agendas públicas para as reformas e sua releitura no cotidiano das práticas da formação: o caso da disciplina Trabalho de Campo Supervisionado. In: Pinheiro R, Mattos RA, organizadores. Construção social da demanda: direito à saúde, trabalho em equipe, participação e espaços públicos. Rio de Janeiro: Cepesc/UERJ/ABRASCO; 2005. p. $129-45$.

3. Universidade Federal do Espírito Santo (UFES). Colegiado do Curso de Graduação em Enfermagem. Currículo do Curso de Graduação em Enfermagem. Vitória; 2005.

4. Barros NF, Cecatti GJ, Turato RE. Pesquisa qualitativa em saúde: múltiplos olhares. São Paulo: Unicamp/ FCM; 2005.

5. Coutinho FA. Construção de um perfil conceitual de vida [tese]. Belo Horizonte (MG): Universidade Federal de Minas Gerais; 2005.

6. Maturana H. Transformación en la convivencia. Santiago: Dolmen Ediciones; 1999.

7. Boff L. Saber cuidar: ética do humano-compaixão pela terra. Rio de Janeiro: Vozes; 1999

8. Merhy EE. Saúde a cartografia do trabalho vivo. São Paulo: Hucitec; 2002.

9. Lima RCD. Enfermeira: uma protagonista que produz o cuidado no cotidiano do trabalho em saúde. Vitória: Edufes; 2001.

10. Lima RCD. O processo de cuidar na enfermagem: mudanças e tendências no mundo do trabalho. Cogitare Enferm. 2005;10(1):63-7. 